\title{
THERMAL COMFORT TRENDS AND VARIABILITY IN THE CROATIAN AND SLOVENIAN MOUNTAINS
}

\author{
K. Zaninović ${ }^{1}$, T. Cegnar ${ }^{2}$, A. Matzarakis ${ }^{3}$ \\ ${ }^{1}$ Meteorological and Hydrological Service of Croatia, Grič 3, HR-10000 Zagreb, Croatia \\ ${ }^{2}$ Environmental Agency of the Republic of Slovenia, Meteorological Office, Vojkova 1b, Ljubljana, Slovenia \\ ${ }^{3}$ University of Freiburg, Meteorological Institute, Werderring 10, D-79085 Freiburg, Germany \\ E-mail: zaninovic@cirus.dhz.hr
}

\begin{abstract}
Mountain meteorological stations played an extremely important role in weather forecasting in the past because they were the only available data source on meteorological conditions several hundred metres above the sea level. Nowadays they are mainly used to estimate the climatic variations and the climate change trends in the environment that is not under the direct influence of the local anthropogenic factors. Two mountain meteorological observatories were chosen to illustrate climatic and bioclimatic trends and variability, Zavižan in Croatian Dinaric Alps and Kredarica in Slovenian Julian Alps. Both have the same monitoring protocol and similar instruments. Because of their unchanged surrounding since time of establishment the data from both observatories are extremely valuable for studying changes in sensitive mountain ecosystems in both countries. Data from the period 1955-2004 were used to assess mountain climatic and bioclimatic variability and trends in Croatia and Slovenia. Results point at the significant increase in the thermal bioclimate index (PET) based on the human energy balance models. At both sites the increase is mainly caused by temperature changes.
\end{abstract}

Keywords - physiological equivalent temperature (PET), variability and trends, Dinaric Alps, Julian Alps,

\section{INTRODUCTION}

As opposed the low-lying stations that are often under the direct influence of the local anthropogenic factors such as urbanization and its thermal island, at the high-lying stations only the large-scale anthropogenic factors should be eventually present. Because of that the detection of climate changes at high elevation sites have a great importance in investigation of global climate change.

Zavižan (1594 m a.s.1., $44^{\circ} 49^{\prime} \mathrm{N}$ and $14^{\circ} 59^{\prime} \mathrm{E}$,) is the highest and most beautiful place on Velebit, a mountain ridge, which extends in the direction northwest-southeast. Velebit is a natural border between mediterranean climate on one side and continental climate, on the top of the ridge mountain climate prevails. It is amazing how climatic conditions change from Mediterranean to sub alpine on a very short distance from north Adriatic islands below Velebit to the top of Velebit. Climatic variety is reflected also by changes in vegetation. Zavižan group is situated in the mid part of north Velebit. It consists of many peaks above 1600 meters. Near the summit trees are stunted because of extreme winds. Summit is rocky, strewn with some dwarf pine and stunted fir. Trademarks of Zavižan are soft grassy slopes and undulating plateaus, beautiful mixed forests of beech and spruce, rocky peaks which rise above them and magnificent sea views. Because of constantly open hut Zavižan is fantastic to visit in winter and is becoming more and more popular among tour skiers. It is also hikers paradise. At Zavižan there is the highest meteorological observatory in Croatia. It started to operate on October $1^{\text {st }} 1953$ and operates without interruptions since than. During the last years meteorological measurements were complemented with ecological monitoring too. Meteorologist Božidar Kirigin was the most meritorious for establishment of Zavižan meteorological station. Meteorological data from Zavižan are included in weather reports, and many climatological studies are based on or take into account data from Zavižan.

The highest mountain station in Slovenia is the observatory at Kredarica in the Julian Alps (2514 m a.s.l., $46^{\circ} 22^{\prime} \mathrm{N}$ and $\left.13^{\circ} 51^{\prime} \mathrm{E}\right)$. The Hydrometeorological Institute of Slovenia established it in 1954 and since then observations and measurements have been performed without any interruption. But the interest to monitor the weather conditions in high mountains has a longer history. The first hut at Kredarica was built in 1896, with this a condition to establish a mountain observatory was fulfilled. Meteorological monitoring at Kredarica started in 1897, the first meteorological observer was the hut-keeper Anton Pekovec. Meteorological data were 
collected only during summer when the hut was opened. The last data from that first period of observations are for the summer 1912. There was a strong interest to reestablish meteorological observations at Kredarica after World War II. There was also a plan to build a meteorological observatory on the top of the mount Triglav, but the option to preserve the peak of the mountain in its natural beauty prevailed. In August 1954 the Hydrometeorological Institute of Slovenia started to perform meteorological observations 3 times per day (at 7 a.m., 2 and 9 p.m.) at Kredarica. In April 1991 24-hours per day observations were introduced, and a stuff of 5 observers at Kredarica. From 1994 at Kredarica an automatic measuring station was installed. Although the importance of Kredarica and also other high mountain observatories is decreasing with the adoption of new remote observing techniques and the introduction of radio-soundings in Ljubljana, Kredarica remains the highest meteorological station in Slovenia, being important for the aspect of alpinismus, monitoring of climate variations and change. The meteorological data from the observatory Kredarica, located about $500 \mathrm{~m}$ away from Triglav glacier, are also suitable for studying the impact of climate variability and change on glacier's melting rate. The hut at Kredarica was rebuilt and enlarged in 1983, life at Kredarica has become more comfortable and safer also for the meteorological observers.
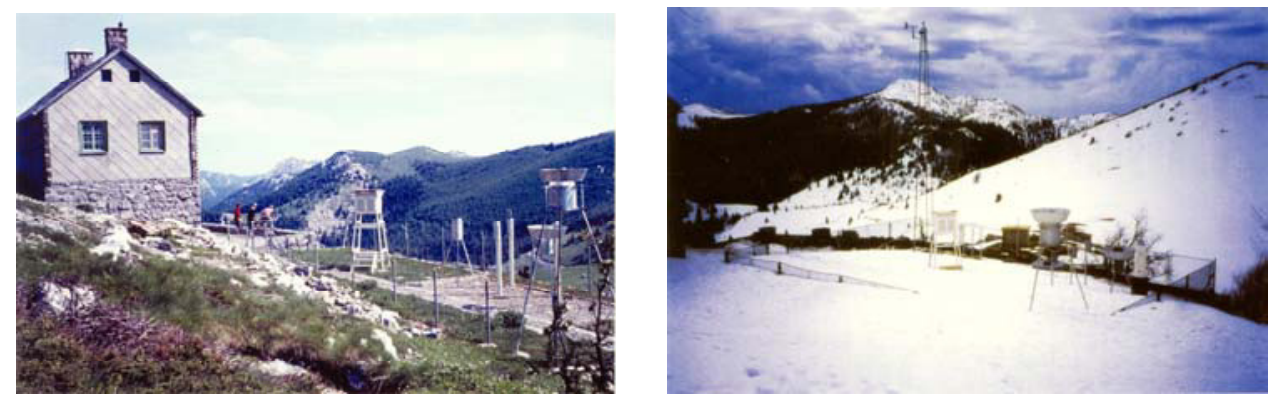

Figure 1: Meteorological observing site at Zavižan, left: during the period 1962-1964 (Photo: I. Baljić), right: in the year 2000 (Photo: A. Vukušić)
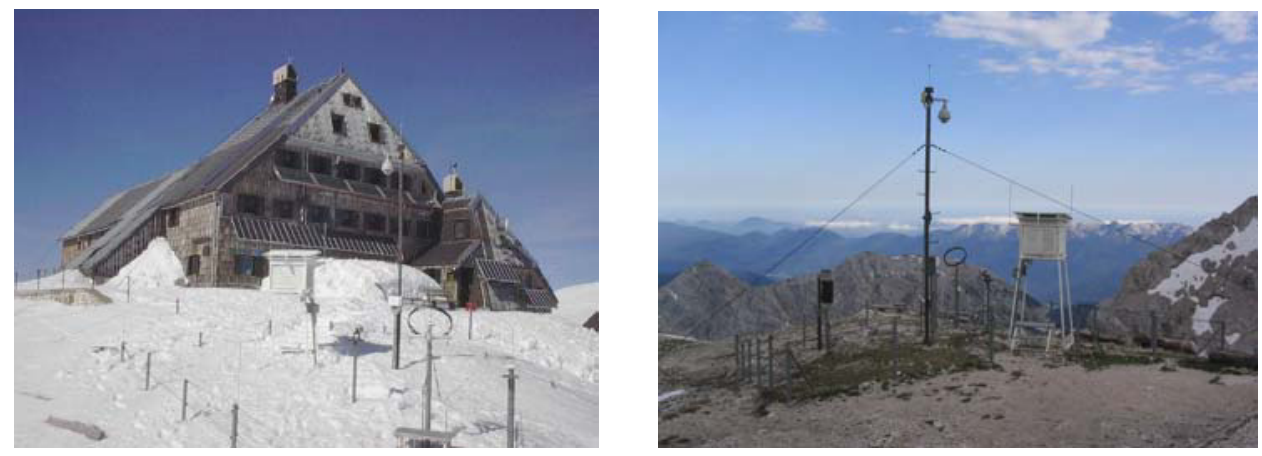

Figure 2: Meteorological observing site at Kredarica, left: during winter (Photo: J. Gartner), right: during summer (Photo: Š. Arhar)

\section{DATA AND METHOD}

The thermal effective complex deals with the influences of the thermal environment on the well-being and health of human beings. The basis for this is the close relationship between the human thermoregulatory mechanism and the human circulatory system. For the physiologically significant assessment of the thermal environment, some thermal indices are available which are derived from the human energy balance (Mayer, 1993, Matzarakis and Mayer, 1997, VDI, 1998, Höppe, 1999 and Matzarakis et al., 1999).

The fluctuations and trends of seasonal and annual values of the thermal comfort index physiological equivalent temperature PET as well as the meteorological parameters that influence thermal comfort (air temperature, relative humidity, wind speed and cloudiness), were determined. Variations and trends were analysed during the period of 1955-2004. In order to remove short-term fluctuations the data series was smoothed by means of the weighted 11-year binomial moving average filter. The linear trend has been tested for significance by 
means of the nonparametric Mann-Kendall rank statistics $t$ (Mitchell et al., 1966, Sneyers, 1990). For the annual PET series a progressive analysis of the time series by means of the statistic $u(t)$ was performed in order to determine the beginning of this phenomenon by means of a sequential analysis (Sneyers, 1990).

\section{RESULTS}

According to the mean annual and seasonal PET values, the mean annual thermal sensation at Zavižan and Kredarica in the period $1955-2004$ was very cold $\left(0.6^{\circ} \mathrm{C}\right.$ and $-5.4^{\circ} \mathrm{C}$ respectively), varying from very cold winters $\left(-10.8^{\circ} \mathrm{C}\right.$ and $\left.-14.3^{\circ} \mathrm{C}\right)$ to cold summers at Kredarica $\left(4.2^{\circ} \mathrm{C}\right)$ and cool summers at Zavižan $\left(11.9^{\circ} \mathrm{C}\right)$. Spring and autumn were very cold, but because of the maritime influence at both locations, autumn was warmer than spring at both locations. Comparing the air temperature and PET one can conclude that at higher elevations the thermal regime is lower than air temperature. The differences are the greatest during winter, due to wind. The differences are lowest in summer, and are mainly the result of more convective clouds in higher elevations during summer.

\subsection{Variations}

At the beginning of the observing period the PET values at Zavižan and Kredarica are not simultaneous (Fig 3). At Zavižan there was a warming from the beginning until the mid 60's, and then cooling until mid 70's, while at Kredarica the cooling is evident from the beginning of the period until early 80 's. After that both locations showed the warming until the end of the period. As the temperatures at both stations decreased from the beginning of the period until 1980, the reason for the warming in PET at Zavižan at the very beginning of the period is the simultaneous decrease in wind speed. In the second part of period the warming is evident at both stations.
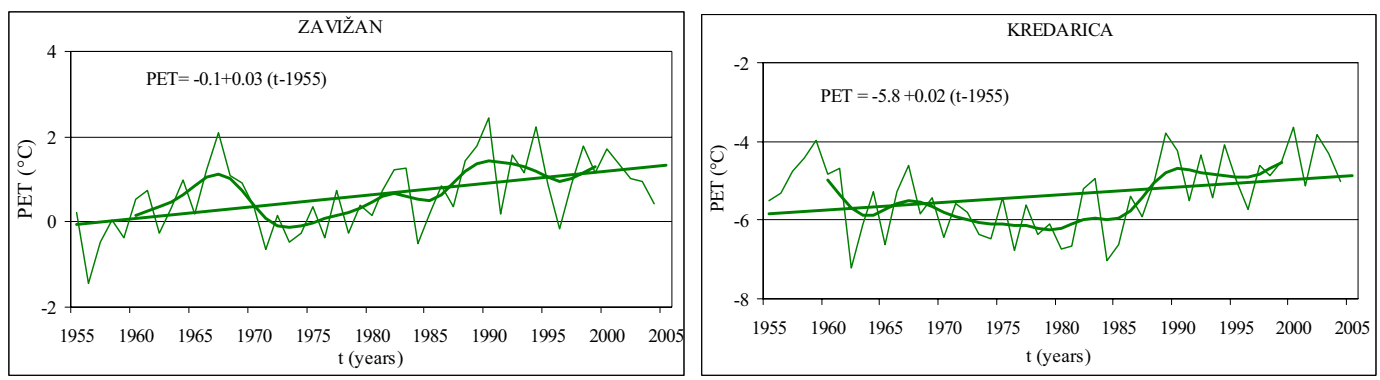

Figure 3. Annual variations of the physiologically equivalent temperature $\left(\mathrm{PET}\right.$ in $\left.{ }^{\circ} \mathrm{C}\right)$, weighted 11 -year binomial moving average series, and linear trends during the period of 1955-2004 at Zavižan and Kredarica.

\subsection{Trend analysis}

At both locations the PET showed increasing trends in annual values $\left(0.3^{\circ} \mathrm{C} / 10\right.$ years at Zavižan and $0.2^{\circ} \mathrm{C} / 10$ years at Kredarica) and in all seasons (except autumn at Kredarica). The greatest changes in PET were observed at Zavižan in summer $\left(0.5^{\circ} \mathrm{C} / 10\right.$ years $)$ and at Kredarica in winter $\left(0.4^{\circ} \mathrm{C} / 10\right.$ years $)$, the smallest in autumn at both stations (Tab. 1). However, the trends were significant for annual values at both stations and for spring and summer at Zavižan. These positive trends were primarly the result of increasing temperature trends, significant for spring, summer and year at both locations. At Zavižan the PET trends were even stronger than temperature ones due to decreasing trends in wind speed. The contribution of other parameters significant for thermal comfort to the positive PET trends was less important.

The progressive trend test was applied to the annual values of PET (Fig. 4). From the graphical representation of the onward (u) and backward ( $\left.u^{\prime}\right)$ test series of PET can be seen that at both stations the PET started to increase in 1980. The intersection point between $u$ and $u^{\prime}$, indicating at the beginning of trend, occurred at Zavižan 1981, while u exceeded the 1.96 limit value in 1989, suggesting the beginning of a significant positive trend. At Kredarica the positive trend began in 1988, but it didn't reach the significance limit yet. Analysing by seasons, the positive trends at Zavižan began between 1982 (summer) and 1987 (winter) and at Kredarica between 1988 (winter) and 1998 (spring and summer). The progressive trend test for temperature, with a dominant effect on the positive trend in PET, showed that 
Table 1. Seasonal and annual trends (per 10 years) of mean physiologically equivalent temperature $\left(\right.$ PET in $\left.{ }^{\circ} \mathrm{C}\right)$, temperature $\left(\mathrm{t}\right.$ in $\left.{ }^{\circ} \mathrm{C}\right)$, vapour pressure $(\mathrm{VP}$ in $\mathrm{hPa})$, wind speed $(\mathrm{v}$ in $\mathrm{m} / \mathrm{s})$ and cloudiness C (in tenths) at Zavižan and Kredarica, period 1955-2004. Shading denotes trends significant at the 0.05 level according to Mann-Kendall rank statistics.

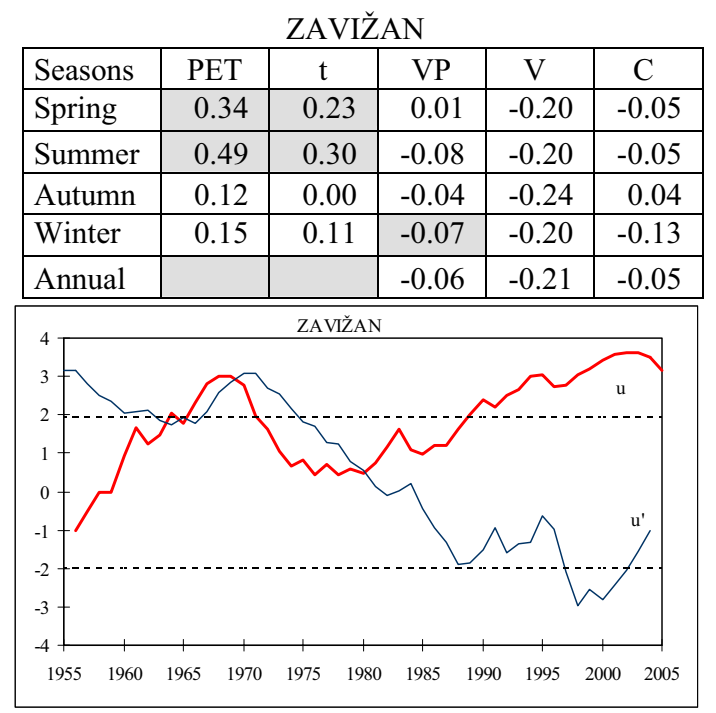

\begin{tabular}{l} 
KREDARICA \\
\begin{tabular}{|l|c|c|c|c|c|}
\hline Seasons & PET & $\mathrm{t}$ & $\mathrm{VP}$ & $\mathrm{V}$ & $\mathrm{C}$ \\
\hline Spring & 0.21 & 0.37 & 0.06 & 0.12 & 0.05 \\
\hline Summer & 0.28 & 0.52 & 0.08 & 0.09 & -0.08 \\
\hline Autumn & -0.03 & 0.12 & 0.03 & 0.05 & 0.11 \\
\hline Winter & 0.36 & 0.35 & -0.00 & 0.09 & -0.10 \\
\hline Annual & 0.18 & 0.27 & 0.04 & 0.07 & -0.00 \\
\hline \hline
\end{tabular} \\
\hline
\end{tabular}

Figure 4. Progressive trend test for annual values of mean physiologically equivalent temperature during the period of 1955-2004 at Zavižan and Kredarica.

the increasing trend began almost simultaneously at both locations - in 1988 at Zavižan and in 1989 at Kredarica, becoming significant few years later (1999 at Zavižan and 1994 at Kredarica).

\section{CONCLUSION}

The highest meteorological observations in Croatia and Slovenia showed the positive trend in thermal comfort as well as in temperature. The result coincides with earlier investigations into the trends in air temperature at Zavižan and at some other high elevated stations in Europe (Gajić-Čapka, Zaninović, 1997). Nevertheless, in spite of considerable increase in thermal comfort in the last 50 years, the bioclimate conditions stayed within the range of the same class of physiological strain for humans.

\section{REFERENCES}

Gajić-Čapka, M.; K. Zaninović, 1997: Changes in Temperature Extremes and Their Possible Causes at the SE Boundary of the Alps, Theor. Appl. Climatol., 57, 89-94

Höppe, P., 1999: The physiological equivalent temperature - a universal index for the biometeorological assessment of the thermal environment, Int J Biometeorol, 43, 71-75.

Matzarakis, A., H. Mayer, 1997: Heat stress in Greece, Int. J. Biometeorol. 41, 34-39.

Matzarakis, A., H. Mayer, M.G. Iziomon, 1999: Applications of a universal thermal index: physiological equivalent temperature, Int. J. Biometeorol, 43, 76-84.

Mayer, H., 1993: Urban bioclimatology, Experientia, 49, 957-963.

Mitchell, J. M.Jr. et al., 1966: Climatic Change. WMO Tech. Note No. 79, pp. 79.

Sneyers, R., 1990: On the Statistical Analysis of Series of Observations, WMO Tech. Note No. 143, pp. 192.

VDI, 1998: Methods for the human-biometerological assessment of climate and air hygiene for urban and regional planning. Part I: Climate, VDI guideline 3787. Part 2. Beuth, Berlin 